\title{
Rheological red blood cell properties in morbidly obese and super obese patients
}

\author{
Amparo Vayáa,*, Ana Sarnago ${ }^{\mathrm{a}}$, Marta Suescun ${ }^{\mathrm{a}}$, Rosa Camara ${ }^{\mathrm{b}}$ and Begoña Laiz ${ }^{\mathrm{a}}$ \\ ${ }^{a}$ Hemorheology and Haemostasis Unit, Service of Clinical Pathology, La Fe University Hospital, \\ Valencia, Spain \\ ${ }^{\mathrm{b}}$ Endocrinology Service, La Fe University Hospital, Valencia, Spain
}

In a recent paper by Wiewiora et al. published in this Journal [7], the authors observed that superobese patients (BMI $>50 \mathrm{~kg} / \mathrm{m}^{2}$ ) show erythrocyte rheological differences when compared with morbidly obese patients (BMI $>40 \mathrm{~kg} / \mathrm{m}^{2}$ ). In this sense, although they did not observe differences in erythrocyte deformability using the LORCA device, they found a higher erythrocyte aggregation index (AI10), a shorter erythrocyte aggregation time (Ta) and a higher erythrocyte disaggregation threshold $(\gamma \mathrm{D})$ in superobese patients when compared with morbidly obese ones. This greater tendency of erythrocytes to aggregate does not seem to be related with either plasmatic lipids or fibrinogen levels, and the authors have no explanation for this feature.

To further clarify this issue, we analyzed the rheological red blood cell properties in morbidly obese patients from a previous published study [6] by evaluating erythrocyte aggregation (AI10, Ta, $\gamma \mathrm{D}$ ) and erythrocyte deformability (EI) at 12, 30 and $60 \mathrm{~Pa}[2,4,5]$, along with biochemical, inflammatory and haematological parameters in 54 morbidly obese subjects and 27 superobese subjects, who were ageand sex-matched qualified for bariatric surgery.

Table 1 shows the differences in the several parameters analysed. Superobese subjects showed higher glucose levels, and AI10 $(P=0.030 ; P=0.012$, respectively), lower Ta and $\gamma \mathrm{D}(P=0.026 ; P=0.007$, respectively).

Pearson's bivariate correlation (Table 2) showed the correlations between erythrocyte aggregation and the other parameters analysed. In the morbidly obese, $\gamma \mathrm{D}$ correlated directly with fibrinogen $(P<0.01)$, but with haematimetric indices MCV and MCH $(P<0.05)$ in the superobese.

The results of the present study indicate that superobese patients showed a higher AI10 and, correspondingly, a lower Ta, which is in agreement with Wiewiora et al. However, $\gamma \mathrm{D}$ was lower than in the morbidly obese subjects, indicating that the cohesion force of the rouleaux formed was lower than in the morbidly obese subjects, which is in disagreement with Wiewiora et al. [7]. This surprising fact may

\footnotetext{
${ }^{*}$ Corresponding author: Amparo Vayá, MD, PhD, Hemorheology and Hemostasis Unit, Service of Clinical Pathology La Fe University Hospital, Avda. de Campanar, 21, 46009 Valencia, Spain. Tel./Fax: +34 963862714; E-mail: vaya_amp@gva.es.
} 
Table 1

Anthropometric, lipidic, haematological and rheological parameters in morbidly obese and superobese subjects

\begin{tabular}{|c|c|c|c|}
\hline & Morbidly obese $(n=54)$ & Superobese $(n=27)$ & $P$ \\
\hline Age (years) & $41 \pm 11$ & $41 \pm 12$ & 0.978 \\
\hline Gender (male/female) & $16 / 38$ & $8 / 19$ & 1.000 \\
\hline Weight (kg) & $118.8 \pm 15.3$ & $144.8 \pm 20.9$ & $<0.001$ \\
\hline BMI $\left(\mathrm{kg} / \mathrm{m}^{2}\right)$ & $44.0 \pm 3.6$ & $55.1 \pm 4.6$ & $<0.001$ \\
\hline Waist (cm) & $127.3 \pm 11.7$ & $140.1 \pm 13.0$ & $<0.001$ \\
\hline Glucose (mg/dL) & $97 \pm 27$ & $125 \pm 60$ & 0.030 \\
\hline Total-cholesterol (mg/dL) & $202 \pm 45$ & $197 \pm 35$ & 0.561 \\
\hline HDL-cholesterol (mg/dL) & $49 \pm 14$ & $50 \pm 12$ & 0.760 \\
\hline LDL-cholesterol (mg/dL) & $127 \pm 36$ & $119 \pm 28$ & 0.304 \\
\hline Triglycerides (mg/dL) & $143 \pm 61$ & $160 \pm 118$ & 0.386 \\
\hline HbA1c (\%) & $5.91 \pm 0.97$ & $6.66 \pm 1.89$ & 0.084 \\
\hline Leptin (ng/mL) & $44.2 \pm 24.6$ & $42.6 \pm 28.4$ & 0.830 \\
\hline Insulin $(\mu \mathrm{UI} / \mathrm{mL})$ & $23.8 \pm 15.5$ & $24.4 \pm 13.8$ & 0.863 \\
\hline CRP (mg/L) & $8.48 \pm 6.73$ & $11.40 \pm 7.75$ & 0.097 \\
\hline Fibrinogen (mg/dL) & $384 \pm 70$ & $391 \pm 70$ & 0.068 \\
\hline EI $12 \mathrm{~Pa}(\%)$ & $46.77 \pm 2.89$ & $45.72 \pm 2.27$ & 0.129 \\
\hline EI $30 \mathrm{~Pa}(\%)$ & $51.24 \pm 2.71$ & $50.42 \pm 2.20$ & 0.176 \\
\hline $\mathrm{EI} 60 \mathrm{~Pa}(\%)$ & $53.12 \pm 2.83$ & $52.64 \pm 2.26$ & 0.445 \\
\hline $\mathrm{Ta}(\mathrm{s})$ & $1.51 \pm 0.40$ & $1.28 \pm 0.33$ & 0.026 \\
\hline AI10 & $56.15 \pm 8.64$ & $64.64 \pm 18.12$ & 0.012 \\
\hline$\gamma \mathrm{D}\left(\mathrm{s}^{-1}\right)$ & $121.6 \pm 104.8$ & $72.22 \pm 25.81$ & 0.007 \\
\hline Haematocrit (\%) & $41.6 \pm 3.1$ & $42.0 \pm 3.6$ & 0.559 \\
\hline MCV (fL) & $87.6 \pm 5.4$ & $87.0 \pm 4.7$ & 0.627 \\
\hline $\mathrm{MCH}$ (pg) & $29.1 \pm 2.1$ & $28.4 \pm 1.9$ & 0.198 \\
\hline MCHC (g/dL) & $33.2 \pm 1.01$ & $32.7 \pm 1.32$ & 0.057 \\
\hline
\end{tabular}

Table 2

Pearson's bivariate correlation in the morbidly obese and superobese between erythrocyte aggregation and the other parameters analysed

\begin{tabular}{|c|c|c|c|c|c|c|}
\hline & \multicolumn{3}{|c|}{ Morbidly obese } & \multicolumn{3}{|c|}{ Superobese } \\
\hline & AI10 & $\mathrm{Ta}$ & $\gamma \mathrm{D}$ & AI10 & $\mathrm{Ta}$ & $\gamma \mathrm{D}$ \\
\hline BMI & & $-0.462^{* *}$ & & & & \\
\hline Glucose & $0.338^{*}$ & & & & & \\
\hline $\mathrm{HbAlc}$ & $0.361^{*}$ & & & & & \\
\hline HDL-cholesterol & & & & $0.515^{*}$ & $0.489^{*}$ & \\
\hline CRP & & $-0.307^{*}$ & & $0.676^{* *}$ & & \\
\hline Fibrinogen & & $-0.582^{* *}$ & $0.494^{* *}$ & & & \\
\hline Haematocrit & $-0.361^{*}$ & & & $-0.481^{*}$ & & \\
\hline $\mathrm{MCV}$ & & & & & & $0.453^{*}$ \\
\hline $\mathrm{MCH}$ & $-0.335^{*}$ & $0.336^{*}$ & & & & $0.450^{*}$ \\
\hline
\end{tabular}

$* P<0.05 ; * * P<0.01$. 
be explained by the results obtained in Pearson's bivariate correlation in which $\gamma \mathrm{D}$ related to plasmatic factors (fibrinogen) in the morbidly obese patients, whereas haematimetric indices (MCV, MCH) were related to $\gamma \mathrm{D}$ in the superobese patients. In other words, in the superobese patients, $\gamma \mathrm{D}$ seems to be associated with intrinsic red blood cell properties, but not with inflammatory parameters. In this sense, it is well-known that both plasma proteins [3] and erythrocyte characteristics may influence erythrocyte aggregation [1].

In conclusion, when compared with the morbidly obese, superobese patients showed higher AI10 and, correspondingly, a lower Ta, but the cohesion of the rouleaux formed was lower and related to red blood cell itself, and not to plasmatic factors. Further research should be performed to shed light on this topic.

\section{References}

[1] O.K. Baskurt and H.J. Meiselman, Blood rheology and hemodynamics, Semin Thromb Hemost 29 (2003), 435-450.

[2] A. Chabanel and M. Samama, Evaluation of a method to assess red blood cell aggregation, Biorheology 26 (1989), $785-797$.

[3] S. Chien and K.M. Jan, Red cell aggregation by macromolecules: Roles of surface adsorption and electrostatic repulsion, J Supramol Struct 1 (1973), 385-409.

[4] P. Mills, D. Quemada and J. Dufaux, Etude de la cinetique d'agregation erythrocytaire dans un écoulement Couette, Rev Phys Appl 15 (1980), 1357-1366.

[5] P. Ruef, J.M.B. Pöschl and O. Linderkamp, The Rheodyn SSD for measuring erythrocyte deformability, Biorheology 32 (1995), 357-358.

[6] A. Vayá, A. Hernández-Mijares, M. Suescun, E. Solá, R. Cámara, M. Romagnoli, D. Bautista and B. Laiz, Metabolic alterations in morbid obesity. Influence on the haemorheological profile, Clin Hemorheol Microcirc 48 (2011), 247-255.

[7] M. Wiewiora, J. Piecuch, M. Glûck, L. Slowinska-Lozynska and K. Sosada, The impacts of super obesity versus morbid obesity on red blood cell aggregation and deformability among patients qualified for bariatric surgery, Clin Hemorheol Microcirc (2014). [Epub ahead of print] DOI: 10.3233/CH-141814 